\title{
PENGGUNAAN KARTU SEHAT GIGI IBU HAMIL (KASIH) SEBAGAI INSTRUMEN PENILAIAN RISIKO PENYAKIT PERIODONTAL DAN KARIES IBU HAMIL DI KOTA MANADO
}

\author{
Youla Karamoy ${ }^{1}$, Vega Roosa Fione ${ }^{2}$ \\ $(1,2)$ Jurusan Kesehatan Gigi Poltekkes Kemenkes Manado jl.RW Monginsidi Malalyang II Manado
}

Email : karamoyyoula@gmail.com,

\begin{abstract}
ABSTRAK
Kesehatan gigi dan mulut yang buruk pada ibu hamil dapat memberikan efek yang tidak baik terhadap bayinya. Tujuan: menganalisis kesesuaian penggunaan kartu KASIH dengan Gold Standar dalam penilaian risiko penyakit periodontal dan karies ibu hamil. Metode: Jenis Penelitian: kuantitatif, desain uji diagnostic dengan pendekatan Cross-Sectional. Teknik pengambilan sampel: Simple Random Sampling pada ibu hamil yang berkunjung di Puskesmas Bahu dan Puskesmas Teling. Jumlah sampel 114, yang berpartisipasi 98 responden. Kegiatan yang dilakukan: wawancara, pengisisan Kartu KASIH dan pemeriksaan karies gigi, penyakit periodontal (gingivitis). Penilaian risiko penggunaan kartu KASIH dan Gold Standar dianalisis menggunakan Uji Kappa dengan $\alpha=0.05$. Hasil: Responden paling banyak berpartisipasi pada penelitian ini berumur 32 tahun $(22,5 \%)$, paling sedikit berumur 19 tahun (6,1\%). Berdasarkan pendidikan terakhir sebagian besar SMU (67,4\%), paling sedikit Diploma $(6,1 \%)$. Berdasarkan jenis pekerjaan, sebagai Ibu rumah tangga paling banyak $(58,2 \%)$ untuk PNS dan Wiraswasta terdata paling sedikit yaitu 5,1\%. Berdasarkan trimester kehamilan, 53,1\% responden usia kehamilannya trimester 2, trimester 1 sebanyak 13,2 \% dan trimester 3 sebanyak 33,7\%. Diketahui nilai Kappa 0,788 dengan nilai Signifikan 0,000 antara kartu Kasih dan pemeriksaan karies, nilai Kappa 0,704 dengan nilai Signifikan 0,000 antara kartu Kasih dan pemeriksaan gingivitis. Nilai koefisiennya menunjukkan adanya korelasi. Nilai Kappa mendekati satu sebagai indikator bahwa Kartu Kasih dengan Gold Standar atau pemeriksaan status karies maupun penyakit periodontal (gingivitis) saling konsisten. Kesimpulan: Kartu Kasih dapat digunakan untuk penilaian risiko penyakit periodontal dan karies gigi.
\end{abstract}

Kata Kunci : kartu KASIH, penyakit periodontal, karies.

\section{ABSTRACT}

Poor oral health in pregnant women can have an adverse effect on their babies. Objective: analyzed the suitability of the use of the KASIH card with the Gold Standard in the risk assessment of periodontal disease and caries in pregnant women. Methods: Types: quantitative. diagnostic test design with a Cross-Sectional approach. Simple Random Sampling of pregnant women visiting the Bahu and Teling Health Centers. The number of samples is 114, who participated 98 respondents. Activities performed: interview, filling in the KASIH Card and examination for dental caries, periodontal disease (gingivitis). The risk assessment of using the KASIH and Gold Standard cards was analyzed using the Kappa test with $\alpha=0.05$. Results: Respondents who participated the most in this study were 32 years old $(22.5 \%)$, at least 19 years old $(6.1 \%)$. Based on the most recent education of high school $(67.4 \%)$, at least Diploma (6.1\%). Based on the type of work, as a housewife the most (58.2\%) for civil servants and self-employed were recorded at the least, namely $5.1 \%$. Based on the trimester of pregnancy, $53.1 \%$ of respondents were in the $2^{\text {nd }}$ trimester, $13.2 \%$ in the 1 st trimester and $33.7 \%$ in the $3^{\text {rd }}$ trimester. It is known that the Kappa value is 0.788 with a 
significant value of 0.000 between the Kasih card and caries examination,the Kappa value of 0.704 with a significant value of 0.000 between the Kasih card and gingivitis examination. The coefficient value shows a correlation. The Kappa value is close to one as an indicator that the Kartu Kasih with Gold Standard or examination of caries status and periodontal disease (gingivitis) is mutually consistent. Conclusion: The Kasih Card can be used for risk assessment of periodontal disease and dental caries.

Keywords: KASIH cards, periodontal disease, caries.

\section{PENDAHULUAN}

Kesehatan gigi dan mulut yang buruk pada ibu terutama ibu hamil dapat memberikan efek yang tidak baik terhadap bayinya seperti kelahiran premature dan berat badan lahir rendah, serta efek buruk terhadap kesehatan gigi dan mulut anak nantinya. Berat badan bayi lahir merupakan penentu yang paling penting dalam pertumbuhan dan perkembangan serta kelangsungan hidup anak. ${ }^{1,2}$

Meskipun bayi dengan BBLR hanya $6-7 \%$ dari semua kelahiran, tetapi $70 \%$ dari kematian neonatal disebab oleh BBLR. $^{4-6}$ Di Indonesia persentase BBLR berdasarkan data Riset Kesehatan Dasar (Riskesdas) 2013 adalah 10,2\% dari semua kelahiran. Persentase tertinggi terdapat di Propinsi Sulawesi Tengah (16.9\%) dan terendah di Propinsi Sumatera Utara (7,2\%), sedangkan persentase BBLR di daerah pedesaan $(11.2 \%)$ lebih tinggi dari pada daerah perkotaan $(9.4 \%){ }^{3}$

Hasil penelitian Santoso di Rumah Sakit Dr. Kariadi Semarang menunjukan bahwa ibu dengan kebersihan mulut yang kurang baik berisiko 2,55 kali melahirkan bayi BBLR kurang bulan dibandingkan ibu dengan kebersihan mulut yang baik. ${ }^{4}$

Selain penyakit periodontal pada ibu hamil yang berpengaruh terhadap kelahiran, karies gigi pada ibu juga memberikan dampak pada anak yang dilahirkan. . Ibu merupakan reservoir utama darimana bayi memperoleh Streptoccocus Mutans. Hal ini berarti resiko karies pada anak secara langsung berhubungan dengan mikrooorganisme yang ada pada ibunya. Kolonisasi awal dari S.mutans merupakan faktor risiko utama untuk terjadinya Early Clinical Caries (ECC) dan karies gigi di masa depan. Untuk itu ECC sangat merugikan dan memberikan dampak negative terhadap kualitas hidup anak dimasa depan. Data WHO menunjukan bahwa Indonesia merupakan Negara dengan keparahan karies tertinggi pada kelompok umur 5-6 tahun yaitu dengan rata-rata def-t 8 yang didominasi oleh komponen decayed sebesar 7,8 gigi per-anak. Penelitian Setiawati, 2012 menunjukkan prevalensi ECC anak usia 6-24 bulan di DKI Jakarta $36,8 \%$ dengan tingkat keparahan 1,52 gigi per-anak. ${ }^{5,6}$

Penyakit periodontal pada ibu menjadi faktor risiko independen terhadap terjadinya BBLR. Kelahiran premature dan berat badan lahir rendah merupakan penyebab dari kematian pada bayi, biaya pengobatan yang tinggi dan masalah emosional khususnya pada ibu. Sedangkan risiko karies pada anak secara langsung berhubungan dengan bakteri yang terdapat pada ibunya. Untuk itu perawatan gigi selama kehamilan sangat penting untuk kesejahteraan wanita dan anak-anaknya. ${ }^{5,7}$

Penilaian risiko dan intervensi dengan menggunakan strategi pencegahan dini yang dimulai sejak kehamilan terbukti efisien sehubungan dengan pencegahan penyakit gigi dan mulut terutama penyakit periodontal dan karies gigi. Kebanyakan ibu hamil tidak menerima informasi tentang kesehatan mulut sedini mungkin untuk mengambil tindakan yang tepat sebelum dan selama kehamilan. Sebagian besar ibu hamil dengan kesehatan gigi dan mulut yang buruk tidak berkonsultasi 
dengan dokter gigi. Ibu hamil memiliki akses terbatas terhadap layanan kesehatan gigi dan mereka juga tidak menerima informasi tentang kesehatan gigi dari penyedia layanan antenatal. Di Australia salah satu cara untuk mengatasi masalah ini adalah dengan pendekatan multidisiplioner, penggunaan kartu perawatan kesehatan sebagai wadah untuk dapat akses ke pelayanan kesehatan gigi. Upaya ini juga telah diterapkan di negara Victoria namun negara-negara lain belum melakukan upaya ini termasuk Indonesia. ${ }^{9}$ Tenaga pelayanan kesehatan primer yang dilatih khususnya tentang kesehatan mulut dapat membantu melakukan deteksi dini penyakit dan memberikan perawatan esensial. Dokter dan bidan adalah titik kontak pertama pelayanan kesehatan dan dapat memainkan peran penting dalam mendidik ibu hamil serta meningkatkan kesadaran mereka tentang pentingnya kesehatan gigi dan mulut selama kehamilan. Kegiatan integrasi antara antenatal dan kesehatan mulut dapat digabungkan melalui pedoman atau monitoring yang terpadu. Hal ini akan memberikan kesepakatan dari semua professional kesehatan tentang pentingnya perawatan kesehatan gigi dan mulut selama kehamilan. ${ }^{9}$

Kartu Sehat Gigi Ibu Hamil (KASIH) merupakan pengembangan model deteksi dini risiko penyakit gigi dan mulut pada ibu hamil sebagai upaya peningkatan kegiatan integritas KIA dan Gigi. Tidak adanya monitoring kesehatan gigi dan mulut pada ibu hamil di Kota Manado menyebabkan tidak tersedianya data kesehatan gigi dan mulut ibu hamil. Penilaian klinis penyakit gigi dan mulut pada ibu hamil memerlukan keterampilan professional, dengan pengembangan model kartu sehat ibu sebagai instrument untuk menilai kesehatan gigi dan mulut ibu hamil diharapkan dapat membantu pencapaian tujuan MDGs yaitu peningkatan kesehatan ibu dan anak melalui peningkatan kesehatan gigi dan mulut.

\section{METODE}

Jenis penelitian ini yaitu penelitian kuantitatif, desain penelitian yang digunakan adalah uji diagnostic dengan pendekatan Cross-Sectional. ${ }^{10}$

Teknik pengambilan sampel yaitu Simple Random Sampling pada ibu hamil yang berkunjung di Puskesmas Bahu dan Puskesmas Teling. Jumlah sampel 114, yang berpartisipasi 98 responden. Dalam penentuan sampel didasarkan pada kriteria inklusi, yaitu : Ibu hamil yang berkunjung ke puskesmas pada saat penelitian dan pengambilan data dalam kondisi fisik dapat dilakukan pemeriksaan; Ibu yang bersedia menjawab pertanyaan dan dilakukan pemeriksaan intra oral, serta mengisi inform consent.

Kegiatan yang dilakukan: wawancara, pengisisan Kartu KASIH dan pemeriksaan karies gigi, penyakit periodontal (gingivitis). Penilaian risiko penggunaan kartu KASIH dan Gold Standar dianalisis menggunakan Uji Kappa dengan $\alpha=0.05$.

\section{HASIL}

1. Distribusi karakteristik responden berdasarkan umur dapat dilihat pada gambar 1

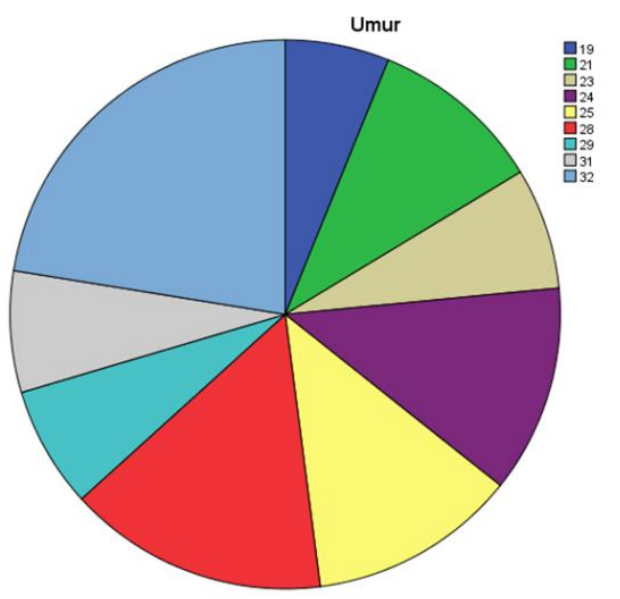


Pada gambar 1 dapat dilihat bahwa terlihat bahwa responden yang paling banyak berpartisipasi pada penelitian ini berumur 32 tahun yaitu berjumlah 22 orang $(22,5 \%)$. Sedangkan yang paling sedikit adalah responden yang berumur 19 tahun sebanyak 6 orang $(6,1 \%)$. Ada 3 kategori umur yang jumlahnya sama masingmasing 7 responden yaitu umur 23, 29 dan 31 tahun.

2. Distribusi karakteristik responden berdasarkan pendidikan terakhir dapat dilihat pada gambar 2

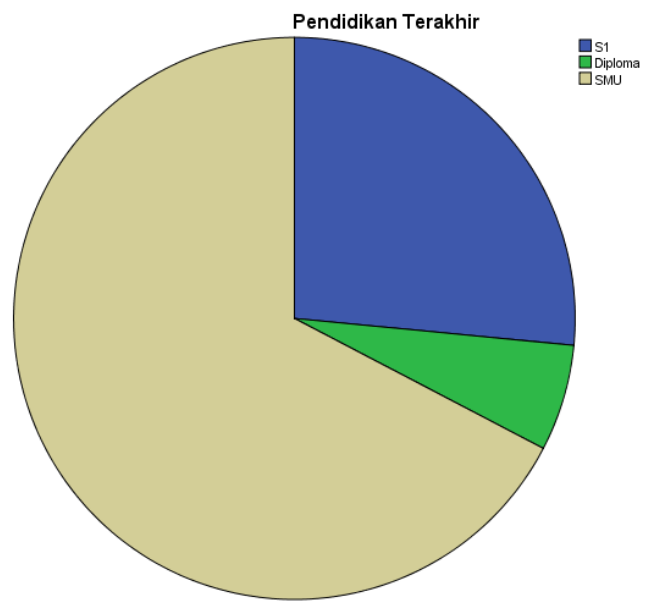

Pada gambar 2 terlihat bahwa responden yang berpartisipasi pada penelitian ini sebagian besar berpendidikan SMU yaitu 66 orang $(67,4 \%)$. Sedangkan yang paling sedikit adalah responden dengan tingkat pendidikan Diploma sebanyak 6 orang $(6,1 \%)$.

3. Distribusi karakteristik responden berdasarkan pekerjaan dapat dilihat pada gambar 3



Gambar 3 menunjukkan bahwa jumlah responden yang bekerja sebagai Ibu rumah tangga paling banyak yaitu $58,2 \%$. Sedangkan responden yang bekerja sebagai PNS dan Wiraswasta terdata paling sedikit yaitu masing-masing 5 orang atau

5,1 $\%$.

4. Distribusi karakteristik responden berdasarkan trimester kehamilan dapat dilihat pada tabel 1

\begin{tabular}{llll}
\hline & Variabel & $\mathbf{f}$ & $\mathbf{\%}$ \\
\hline \multirow{2}{*}{ Usia } & Trimester 1 & 13 & 13,2 \\
Kehamilan & Trimester 2 & 52 & 53,1 \\
& Trimester 3 & 33 & 33,7 \\
& Jumlah & $\mathbf{9 8}$ & $\mathbf{1 0 0}$ \\
\hline
\end{tabular}

Pada tabel 1 terlihat bahwa Responden yang berpartisipasi pada penelitian ini ada $53,1 \%$, responden yang usia kehamilannya termasuk pada trimester

5. Hasil Uji Kappa tabel 2 x 2
2. Untuk responden yang usia kehamilannya pada trimester 1 sebanyak $13,2 \%$ dan trimester 3 sebanyak $33,7 \%$. 
Tabel 2. Hasil Uji Kappa Kartu Kasih dan Gold Standar/Pemeriksaan Karies

\begin{tabular}{|lr|r|r|r|r|}
\hline & \multicolumn{1}{|c|}{ Value } & $\begin{array}{c}\text { Asymp. Std. } \\
\text { Error }^{\mathrm{a}}\end{array}$ & Approx. $\mathrm{T}^{\mathrm{b}}$ & Approx. Sig. \\
\hline $\begin{array}{l}\text { Measure of Agreement } \\
\text { N of Valid Cases }\end{array}$ & Kappa & .788 & .082 & 7.981 & .000 \\
\hline
\end{tabular}

a. Not assuming the null hypothesis.

b. Using the asymptotic standard error assuming the null hypothesis.

Pada tabel 2 terlihat bahwa nilai Kappa 0,788 dengan nilai Signifikan 0,000 menandakan bahwa nilai koefisiennya menunjukan adanya korelasi.

Tabel 3. Hasil Uji Kappa Kartu Kasih dan Gold Standar/Pemeriksaan Gingivitis

\begin{tabular}{|lc|r|r|r|r|}
\hline & \multicolumn{1}{|c|}{ Symmetric Measures } \\
\hline $\begin{array}{l}\text { Measure of Agreement } \\
\text { N of Valid Cases }\end{array}$ & $\begin{array}{c}\text { Asymp. Std. } \\
\text { Error }^{\mathrm{a}}\end{array}$ & Approx. T & Approx. Sig. \\
\hline
\end{tabular}

a. Not assuming the null hypothesis.

b. Using the asymptotic standard error assuming the null hypothesis.

Pada tabel 3 terlihat bahwa nilai Kappa 0,704 dengan nilai Signifikan 0,000

\section{PEMBAHASAN}

Kehamilan menyebabkan terjadinya perubahan-perubahan baik anatomi maupun fisiologi pada ibu. Untuk itu dalam kehamilan terjadi adaptasi ibu dalam bentuk fisik dan psikologis. Perubahan-perubahan ini dapat mempengaruhi sistem kesehatan dalam tubuh dan juga menyebabkan perubahan pada beberapa bagian tubuh termasuk rongga mulut. Perubahan psikologis seperti perubahan pola makan, rasa mual dan muntah, rasa lesu dan lemah selama kehamilan menyebabkan ibu hamil sering kali mengabaikan kebersihan dirinya termasuk kebersihan gigi dan mulutnya. ${ }^{12}$

Pada tabel 1 terlihat bahwa Responden yang paling banyak berpartisipasi pada penelitian ini yaitu responden yang usia kehamilannya termasuk pada trimester $2(53,1) \%$. Sedangkan ibu hamil yang usia kehamilannya pada Trimester 1 dan 3 menandakan bahwa nilai koefisiennya menunjukan adanya korelasi

hanya sedikit atau kurang dari 50\%. Hal ini disebabkan karena adanya kekhawatiran dari ibu hamil bahwa jika merawat gigi pada saat hamil akan berpengaruh pada proses kehamilannya. Sehubungan dengan hal tersebut maka dalam rangka mengurangi faktor kecemasan dan kekhawatiran dari ibu hamil maka pada penelitian ini digunakan kartu KASIH untuk dapat menilai risiko terjadinya penyakit periodontal dan karies gigi.

Pada tabel 2 terlihat bahwa nilai Kappa 0,788 dengan nilai Signifikan 0,000 menandakan bahwa nilai koefisiennya menunjukan adanya korelasi. Pada tabel 3 terlihat bahwa nilai Kappa 0,704 dengan nilai Signifikan 0,000 menandakan bahwa nilai koefisiennya menunjukan adanya korelasi. Diharapkan nilai Kappa mendekati satu sebagai indikator bahwa Kartu Kasih dengan Gold Standar atau pemeriksaan status karies maupun 
penyakit periodontal (gingivitis) saling konsisten. Berdasarkan hasil penelitian ini dapat menunjukkan bahwa nilai Kappa yang diperoleh hampir mencapai angka satu sehingga dapat dikatakan bahwa antara hasil penilaian penyakit periodontal menggunakan kartu Kasih dengan pemeriksaan oleh Gold Standar adalah saling konsisten.

Penggunaan kartu Kasih dapat mengurangi masalah dimana ibu hamil tidak menerima informasi tentang kesehatan mulut sedini mungkin untuk mengambil tindakan yang tepat sebelum dan selama kehamilan. Hal ini di dukung oleh penelitian di Australia, dimana salah satu cara untuk mengatasi masalah ini adalah dengan pendekatan multidisiplioner, penggunaan kartu perawatan kesehatan sebagai wadah untuk dapat akses ke pelayanan kesehatan gigi. Upaya ini juga telah diterapkan di negara Victoria. $^{9,1}$

Disamping itu penggunaan kartu Kasih merupakan salah satu alternative untuk mengurangi tingkat kecemasan ibu hamil dalam merawat kesehatan gigi dan mulutnya selama masa kehamilan. Sehingga walaupun terjadi perubahan psikologis yang dialami wanita hamil tidak akan menyebabkan ibu hamil mengabaikan kebersihan dirinya termasuk kebersihan gigi dan mulutnya. Karena jika hal ini terjadi maka dapat memperburuk status kesehatan gigi dan mulut ibu hamil, yang pada akhirnya menyebabkan ibu hamil rentan terhadap penyakit gigi dan mulut. Untuk itu perawatan gigi selama kehamilan sangat penting untuk kesejahteraan wanita dan anak-anaknya nanti. ${ }^{13}$

Melalui pengisian pada kartu Kasih, ibu hamil dapat mengetahui gambaran kesehatan gigi dan mulutnya. Sehingga dapat melakukan upaya-upaya diri untuk meminimalisir dan mengurangi resiko terjadinya masalah karies gigi dan penyakit periodontal selama masa kehamilan.
Penggunaan kartu Kasih untuk ibu hamil ini sangat diharapkan dapat dilakukan di Puskesmas-puskesmas khususnya di Kota Manado yang memang belum menggunakan kartu ini. Padahal kartu ini sudah ada sejak tahun 2012 namun belum begitu banyak dimanfaatkan. Penggunaan kartu ini sangat mudah. Kartu ini bisa digunakan oleh Bidan pada saat bersamaan waktu ibu hamil kontrol kehamilannya di Puskesmas atau Pos-pos bersalin yang ada.

\section{SIMPULAN}

Simpulan pada penelitian ini adalah adanya korelasi antara Kartu Kasih dengan Gold Standar atau pemeriksaan status karies dengan nilai koefisien menunjukan saling konsisten. Adanya korelasi antara Kartu Kasih dengan Gold Standar atau pemeriksaan status penyakit periodontal (gingivitis) dengan nilai koefisien menunjukan saling konsisten. ${ }^{14}$

\section{SARAN}

Setelah membahas hasil penelitian ini, maka yang menjadi saran adalah :

1. Bagi ibu hamil yang takut dengan pemeriksaan gigi langsung saat hamil dapat meminta pelayanan menggunakan kartu Kasih.

2. Sebagai bahan pertimbangan untuk pengembangan program yang terintegrasi Bidang Kesehatan Gigi dan Kesehatan Ibu Anak di Puskesmas

3. Sebagai bahan acuan dalam memberikan edukasi kepada ibu hamil tentang pentingnya memelihara kesehatan gigi.

\section{DAFTAR PUSTAKA}

1. World FDI, Federation D. Oral Health "A Report by FDI World Dental FederatioN ." WOHD. 2014:1-24.

2. Buerlein JK, Horowitz AM, Child WL. Perspectives of Maryland Women Regarding Oral Health During Pregnancy and Early 
Childhood. J Public Health Dent. 2011;71(2):131-135.

3. Kemenkes RI. Pengembanga dan Riset Kesehatan Dasar (Riskesdas) 2013. Jakarta; 2013:163-182.

4. Santoso O, SR WA, Dwi Retnonigrum. Hubungan Kebersihan Mulut dan Gingivitis Ibu Hamil Terhadap Kejadian Bayi Berat Badan Lahir Rendah Kurang Bulan di RSUP Dr Kariadi Semarang dan Jejaringnya. Media Med Indones. 2009;43:288-294.

5. Meyer K, Geurtsen W, Günay H. An Early Oral Health Care Program Starting During Pregnancy: Results of a Prospective Clinical Long-Term Study. Clin Oral Investig. 2010;14(3):257-64

6. Petersen PE. Priorities for Research for Oral Health in the 21st Century-the Approach of the WHO Global Oral Health Programme. Community Dent Health. 2005;22(2):71-4.

7. Haerian-ardakani A, Eslami Z, Rashidi-meibodi F, et al. Relationship between maternal periodontal disease and low birth weight babies. Iran J Reprod Med. 2013;11(8):625-630.

8. Kloetzel MK, Huebner CE, Milgrom P, Littell CT, Eggertsson $\mathrm{H}$. Oral health in pregnancy: educational needs of dental. $J$ Public Health Dent. 2012:279-286.
9. George a, Johnson M, Blinkhorn a, et al. The oral health status, practices and knowledge of pregnant women in south-western Sydney. Aust Dent J. 2013;58(1):26-33.

10. Noor PDNN. Epidemiologi. Jakarta. Rineka Cipta. 2008:135147

11. Dahlan MS. Penelitian Diagnostik, Dasar-Dasar Teoritis dan Aplikasi dengan Program SPSS dan Stata. SeriEviden. Jakarta: Salemba Medika; 2009:1-128.

12. Kothiwale $\mathrm{S} \mathrm{V}, \mathrm{Br} \mathrm{D}$. Poor Periodontal Health as a Risk Indicator for Low Birth Weight of the Infants. Indian $J$ Stomatol. 2011;2(3):153-58.

13. Vogt M, Sallum AW, Cecatti JG, Morais SS. Periodontal disease and some adverse perinatal outcomes in a cohort of low risk pregnant women. Reprod Health. 2010;7(1):29.

14. Kemenkes.Pedoman Pemeliharaan Kesehatan Gigi dan Mulut Ibu Hamil dan Anak Usia Balita Bagi Tenaga Kesehatan Di Fasilitas Pelayanan Kesehatan.; 2012:1-6.

15. Dinas Kesehatan Kota Manado. Profil Kesehatan Kota Manado Tahun 2017.; 2017:1-159. 